Article

\title{
Antinociceptive Interaction and Pharmacokinetics of the Combination Treatments of Methyleugenol Plus Diclofenac or Ketorolac
}

\author{
Héctor Isaac Rocha-González ${ }^{1}\left[\right.$, María Elena Sánchez-Mendoza ${ }^{1}$, Leticia Cruz-Antonio ${ }^{2}$, \\ Francisco Javier Flores-Murrieta ${ }^{1,3}$, Xochilt Itzel Cornelio-Huerta ${ }^{1}$ and Jesús Arrieta ${ }^{1, * \mathbb{C}}$ \\ 1 Escuela Superior de Medicina, Instituto Politécnico Nacional, Plan de San Luis y Díaz Mirón, Colonia Casco \\ de Santo Tomás, Miguel Hidalgo, Ciudad de México 11340, Mexico; heisaac2013@hotmail.com (H.I.R.-G.); \\ mesmendoza@hotmail.com (M.E.S.-M.); fjfloresmurrieta@yahoo.com.mx (F.J.F.-M.); \\ xochilt_itz@hotmail.com (X.I.C.-H.) \\ 2 Facultad de Estudios Superiores Zaragoza, UNAM, Av. Guelatao No. 66, Colonia Ejército de Oriente, \\ Iztapalapa, Ciudad de México 09230, Mexico; letycruza@yahoo.com.mx \\ 3 Unidad de Investigación en Farmacología, Instituto Nacional de Enfermedades Respiratorias Ismael Cosió \\ Villegas, Secretaría de Salud, Ciudad de México 14080, Mexico \\ * Correspondence: jearrval@yahoo.com.mx; Tel.: +55-5729-6300 (ext. 62740); Fax: +55-5622-5329
}

Received: 13 October 2020; Accepted: 31 October 2020; Published: 3 November 2020

\begin{abstract}
Although nonsteroidal anti-inflammatory drugs (NSAIDs) are one of the main types of drugs used to treat pain, they have several adverse effects, and such effects can be reduced by combining two analgesic drugs. The aim of this study was to evaluate the nociceptive activity of methyleugenol combined with either diclofenac or ketorolac, and determine certain parameters of pharmacokinetics. For the isobolographic analysis, the experimental effective dose $30\left(\mathrm{ED}_{30}\right)$ was calculated for the drugs applied individually. With these effective doses, the peak plasma concentration $\left(\mathrm{C}_{\max }\right)$ was found and the other parameters of pharmacokinetics were established. Methyleugenol plus diclofenac and methyleugenol plus ketorolac decreased licking behavior in a dose-dependent manner in phase II, with an efficacy of $32.9 \pm 9.3$ and $39.8 \pm 9.6 \%$, respectively. According to the isobolographic analysis, the experimental and theoretical $\mathrm{ED}_{30}$ values were similar for methyleugenol plus diclofenac, suggesting an additive effect, but significantly different for methyleugenol plus ketorolac ( $3.6 \pm 0.5 \mathrm{vs} .7 .7 \pm 0.6 \mathrm{mg} / \mathrm{kg}$, respectively), indicating a probable synergistic interaction. Regarding pharmacokinetics, the only parameter showing a significant difference was $C_{\max }$ for the methyleugenol plus diclofenac combination. Even with this difference, the combinations studied may be advantageous for treating inflammatory pain, especially for the combination methyleugenol plus ketorolac.
\end{abstract}

Keywords: methyleugenol; isobolographic analysis; synergism; diclofenac; ketorolac

\section{Introduction}

Pain is an unpleasant sensory and emotional experience associated with actual or potential tissue damage [1]. It functions as a defense mechanism to safeguard the integrity of the organism against potentially destructive factors. Under certain circumstances, however, pain does not provide a beneficial protective effect, but rather becomes a pathological process that requires treatment [2].

Pain includes motivational, emotional, discriminatory, sensory, affective, and cognitive aspects, which can lead to a low quality of life together with high social and economic costs [3]. Four main types of pain are currently recognized, classified by duration and the physiopathological characteristics: nociceptive, functional, neuropathic, and inflammatory [4]. 
Inflammatory pain results from tissue ruptures, intense pressures, burns, prolonged cold, and chemical injuries. A great variety of compounds are released by the injured cells, and still more are synthesized during post-injury events. Whereas some of these substances directly activate nociceptors, others such as prostaglandins sensitize them [5,6]. COX enzymes are responsible for the synthesis of prostaglandins [7]. The two isoforms of COX (COX1 and COX2) have a distinct distribution and tissue function. COX1 is expressed in basal conditions and synthesizes prostaglandins to perform homeostatic functions, while COX2 expression increases during inflammation and other disease states [8].

Non-steroidal anti-inflammatory drugs (NSAIDs) constitute a major class of analgesic drugs used to relieve inflammatory pain and inflammation through the inhibition of the COX enzymes [7]. Since selective inhibition of COX2 by new NSAIDs (e.g., celecoxib) blocks prostaglandin production at the sites of inflammation, gastric damage caused by the intake of this type of drug is minimal. However, these new NSAIDs have been found to damage the myocardium [9]. Traditional NSAIDs inhibit COX1 and COX2 to a greater or lesser extent, which is relevant in platelets and gastroduodenal mucosa because long-term inhibition can lead to ulcers with bleeding, perforation, or obstruction as well as renal dysfunction, cardiovascular events, and the risk of death [10]. Hence, the prolonged use of NSAIDs has limitations.

One alternative to decrease side effects is the combination of traditional NSAIDs with other types of analgesic drugs that act by a distinct mechanism of action. This allows a broader spectrum of pain relief activity and perhaps a synergistic effect, thereby reducing the individual doses and adverse effects of each drug [11]. One candidate for co-administration with NSAIDs is methyleugenol, a natural product known to have analgesic activity [12]. The aim of the present study was to evaluate (with mice and the formalin test) the analgesic effect of methyleugenol combined with either diclofenac or ketorolac, and determine (in rats) certain parameters of the pharmacokinetics of the two combination treatments at experimental effective dose $30\left(\mathrm{ED}_{30} \mathrm{E}\right)$.

\section{Results}

\subsection{Antinociceptive Effect of the Individual Drugs}

A subcutaneous $2.5 \%$ formalin injection into the right hindpaw of mice elicited a typical biphasic pattern of flinching behavior (Figure 1A). Oral administration of methyleugenol (Figure 1A,B), diclofenac (Figure 1C,D), and ketorolac (Figure 1E,F) significantly reduced licking behavior time in a dose-dependent fashion in phase II, but not phase I of the formalin test. According to the dose-response curve, methyleugenol reached an efficacy of $38.7 \pm 3.9 \%$ at $30 \mathrm{mg} / \mathrm{kg}$ (Figure $1 \mathrm{~B}$ ) and had an $\mathrm{ED}_{30} \mathrm{E}$ of $8.4 \pm 1.0 \mathrm{mg} / \mathrm{kg}$ (Table 1). Likewise, the experimental efficacy values of diclofenac and ketorolac were $30.1 \pm 0.7 \%$ and $50.7 \pm 7.5 \%$, respectively, at $30 \mathrm{mg} / \mathrm{kg}$ (Figure 1D,F). In addition, the $\mathrm{ED}_{30}$ values for the two drugs were $31.6 \pm 2.8 \mathrm{mg} / \mathrm{kg}$ and $7.1 \pm 0.6 \mathrm{mg} / \mathrm{kg}$, respectively (Table 1 ).

Table 1. Antinociceptive effective dose $30\left(\mathrm{ED}_{30}\right)$ were derived from the formalin test applied to mice. Data were established by linear regression of the dose-response curves of methyleugenol, diclofenac, and ketorolac when administered alone.

\begin{tabular}{ccc}
\hline Drug & $\begin{array}{c}\mathbf{E D}_{\mathbf{3 0}} \pm \mathbf{S E M} \\
(\mathbf{m g} / \mathbf{k g})\end{array}$ & $\mathbf{R}^{\mathbf{2}}$ \\
\hline Methyleugenol & $8.4 \pm 1.0$ & 0.983 \\
Diclofenac & $31.6 \pm 2.8$ & 0.997 \\
Ketorolac & $7.1 \pm 0.6$ & 0.992 \\
\hline
\end{tabular}

Abbreviations: SEM = Standard error of the mean, $\mathrm{R}^{2}=$ correlation coefficient.

\subsection{Antinociceptive Effect of the Drug Combinations}

The combination of methyleugenol plus diclofenac at a $1: 1$ dose ratio $(0.52+1.97,1.05+3.95$, $2.09+7.89$, and $4.18+15.78 \mathrm{mg} / \mathrm{kg}$ ) significantly decreased licking time with an efficacy value of 
$32.9 \pm 9.3 \%$ (Figure $2 \mathrm{~A}, \mathrm{C}$ ). The isobolographic analysis indicated that the $\mathrm{ED}_{30} \mathrm{E}$ and $\mathrm{ED}_{30} \mathrm{~T}$ were similar $(19.1 \pm 3.3 \mathrm{mg} / \mathrm{kg}$ and $20.0 \pm 1.5 \mathrm{mg} / \mathrm{kg}$, respectively, Table 2$)$, and that the confidence intervals of $\mathrm{ED}_{30} \mathrm{E}$ and $\mathrm{ED}_{30} \mathrm{~T}$ overlapped (Figure $2 \mathrm{E}$ ). Moreover, the interaction index was about 1 and the interaction index confidence interval crossed this value (Table 2). The statistical and isobolographic analyses evidence the likely additive interaction of the combined methyleugenol plus diclofenac treatment given to mice.
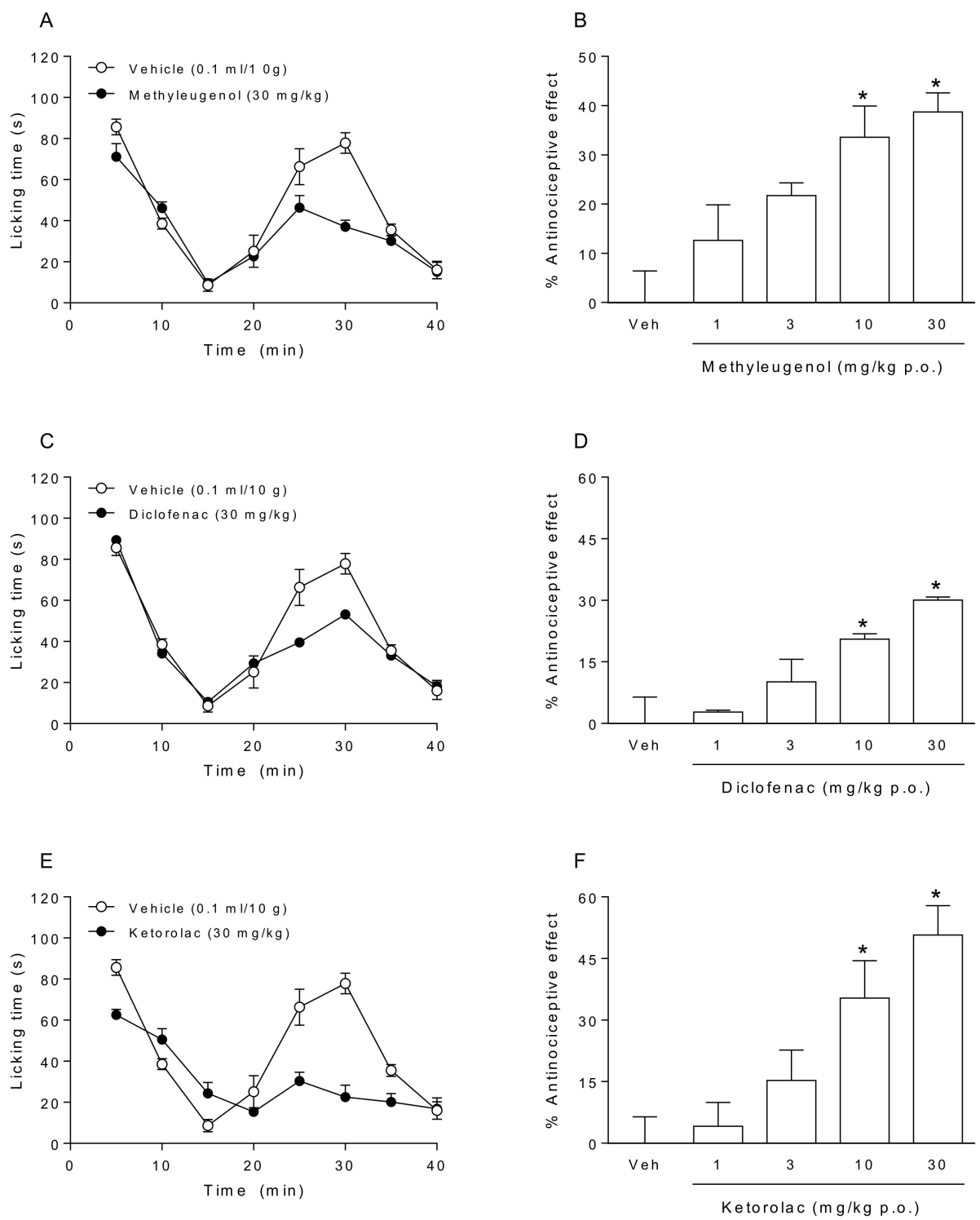

Figure 1. The time course of the antinociceptive effect found for rats after receiving each compound individually: (A) methyleugenol (30 mg/kg), (C) diclofenac (30 mg/kg), and (E) ketorolac (30 mg/kg). Bar graph of the dose-response effect on rats produced by the treatment with the vehicle (Veh), (B) methyleugenol, (D) diclofenac, or (F) ketorolac. The data reflect the results of phase II of the formalin test. Bars depict the mean of the percentage of antinociception \pm SEM for 6-8 animals. ${ }^{*} p<0.05$ versus Veh group, as established by one-way analysis of variance (ANOVA) followed by Tukey's test.

The combination of methyleugenol plus ketorolac at a $1: 1$ dose ratio $(0.52+0.45,1.05+0.89$, $2.09+1.78$, and $4.18+3.56 \mathrm{mg} / \mathrm{kg}$ ) reduced licking time in a dose-dependent manner with an efficacy value of $39.8 \pm 9.6 \%$ (Figure $2 \mathrm{~B}, \mathrm{D}$ ). Interestingly, the $\mathrm{ED}_{30} \mathrm{E}$ of methyleugenol plus ketorolac $(3.6 \pm 0.5 \mathrm{mg} / \mathrm{kg})$ was significantly lower than its $\mathrm{ED}_{30} \mathrm{~T}(7.7 \pm 0.6 \mathrm{mg} / \mathrm{kg}$, Table 2). Furthermore, 
the confidence intervals of the $\mathrm{ED}_{30} \mathrm{E}$ and $\mathrm{ED}_{30} \mathrm{~T}$ did not overlap (Figure $2 \mathrm{~F}$ ), the interaction index was less than 1, and the interaction index confidence interval did not pass through 1 (Table 2). Thus, statistical and isobolographic analyses suggest a synergistic antinociceptive interaction of the combined methyleugenol plus ketorolac treatment administered to mice.
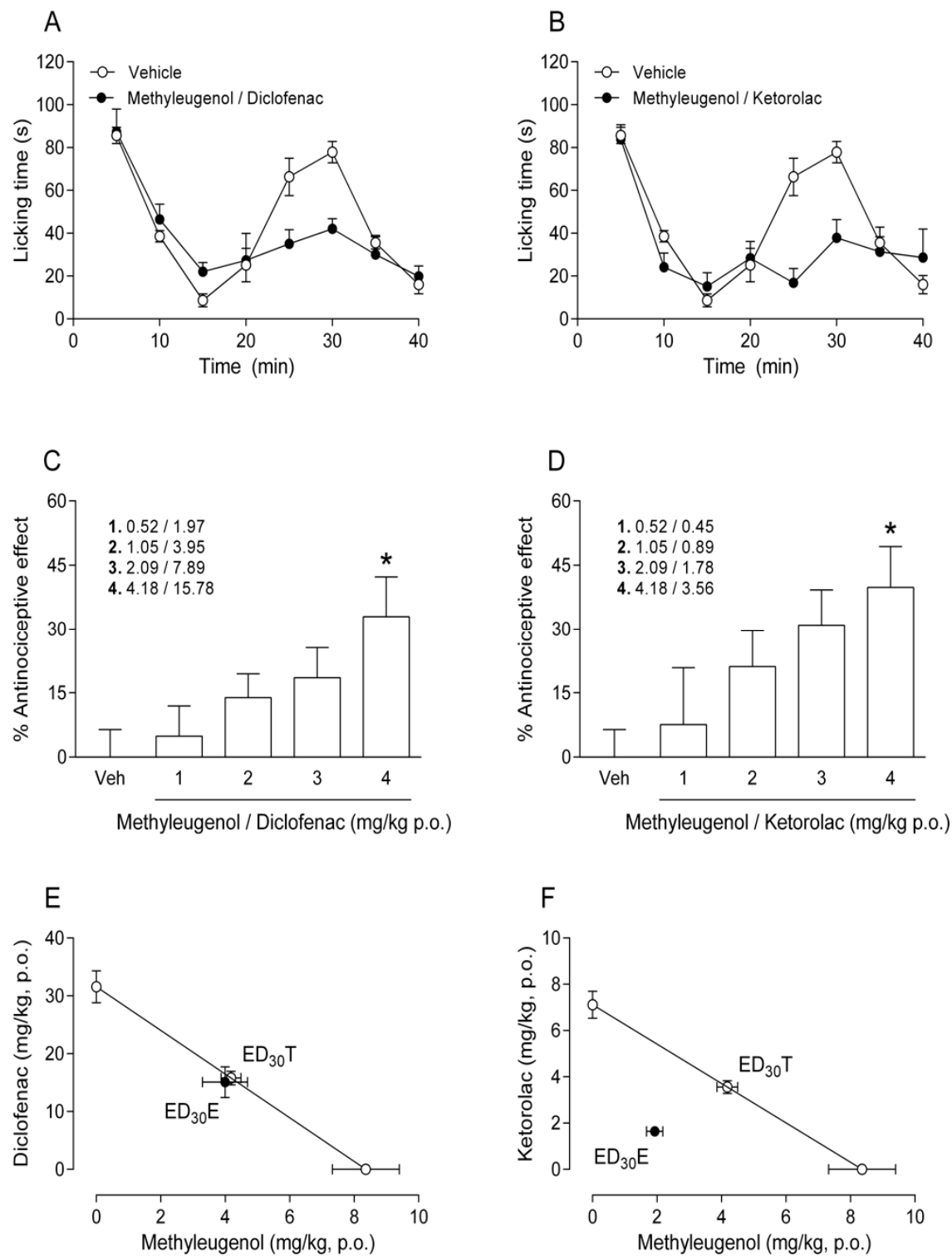

Figure 2. The time course of the antinociceptive effect induced by methyleugenol plus diclofenac (A) or methyleugenol plus ketorolac (B), evaluated by the formalin test. The dose-response effects of the vehicle (Veh), methyleugenol plus diclofenac (C), and methyleugenol plus ketorolac (D). Bars illustrate the mean of the percentage of antinociception \pm SEM for $6-8$ animals. ${ }^{*} p<0.05$ versus the Veh group, determined by one-way analysis of variance (ANOVA) followed by Tukey's test. The isobolographic interaction of methyleugenol plus diclofenac (E) or methyleugenol plus ketorolac (F) at a 1:1 dose ratio. The points on the $X$-axis portray the experimental $\mathrm{ED}_{30}$ values of methyleugenol and those on the $Y$-axis the experimental values of diclofenac or ketorolac. The diagonal line connecting the $\mathrm{ED}_{30}$ of the combination of methyleugenol and diclofenac or ketorolac is the theoretical value of additivity. For each combination, the point designated as $\mathrm{ED}_{30} \mathrm{~T}$ represents the theoretical $\mathrm{ED}_{30}$, and the point labelled $\mathrm{ED}_{30} \mathrm{E}$ indicates the experimental $\mathrm{ED}_{30}$ for each combination. The $\mathrm{ED}_{30} \mathrm{E}$ was statistically different from the $\mathrm{ED}_{30} \mathrm{~T}$ for methyleugenol plus ketorolac but not for methyleugenol plus diclofenac. Differences were examined with the Student's $t$-test, considering significance at $p<0.05$. 
Table 2. Statistical analysis of the effects produced on mice by the administration of methyleugenol plus diclofenac and methyleugenol plus ketorolac. The experimental values were determined by the formalin test.

\begin{tabular}{cccc}
\hline Dose Ratio & $\begin{array}{c}\text { Theoretical } \\
\text { ED }_{\mathbf{3 0}} \pm \mathbf{S E M} \\
(\mathbf{C I} \text { at } \mathbf{9 0} \%)\end{array}$ & $\begin{array}{c}\text { Experimental } \\
\text { ED }_{\mathbf{3 0}} \pm \mathbf{S E M} \\
\mathbf{( C I} \text { at } \mathbf{9 0} \%)\end{array}$ & $\begin{array}{c}\gamma \pm \mathbf{S E M} \\
(\mathbf{C I} \text { at } \mathbf{9 0} \%)\end{array}$ \\
\hline methyleugenol + diclofenac & $20.0 \pm 1.5$ & $19.1 \pm 3.3$ & $0.96 \pm 0.18$ \\
1:1 & $(16.2-24.5)$ & $(9.0-40.5)$ & $(0.63-1.46)$ \\
methyleugenol + ketorolac & $7.7 \pm 0.6$ & $3.6 \pm 0.5 *$ & $0.46 \pm 0.07$ \\
$1: 1$ & $(6.3-9.6)$ & $(2.0-6.2)$ & $(0.33-0.65)$ \\
\hline
\end{tabular}

* Statistically different from the theoretical $\mathrm{ED}_{30}(p<0.05)$, evaluated by the Student's $t$-test. Abbreviations: $\mathrm{SEM}=$ standard error of the mean; $\mathrm{ED}_{30}=$ effective dose 30 (in $\mathrm{mg} / \mathrm{kg}$ ); $\mathrm{CI}=$ confidence interval at $90 \%$; $\gamma=$ interaction index.

\subsection{Effect of Methyleugenol on the Pharmacokinetics of Diclofenac or Ketorolac}

Regarding the pharmacokinetics of diclofenac (Table 3), the $\mathrm{C}_{\max }$ for the individual treatment $(2.80 \pm 0.09 \mu \mathrm{g} / \mathrm{mL})$ was significantly different from the value for methyleugenol plus diclofenac $(1.83 \pm 0.18 \mu \mathrm{g} / \mathrm{mL})$. Hence, the absorption of diclofenac decreased with the combined treatment. However, there was no significant difference between these two treatments for the $\mathrm{AUC}_{0 \rightarrow \mathrm{t}}, \mathrm{AUC}_{0 \rightarrow \infty}$, $\mathrm{t}_{1 / 2}$, or $\mathrm{T}_{\max }($ Table 3 ).

Table 3. Parameters of pharmacokinetics determined after the oral administration of the vehicle plus diclofenac $(15.08 \mathrm{mg} / \mathrm{kg}$ ) or methyleugenol plus diclofenac (3.99 and $15.08 \mathrm{mg} / \mathrm{kg}$, respectively) to rats. Data are expressed as the mean $\pm \operatorname{SEM}(n=6)$.

\begin{tabular}{ccc}
\hline Parameter & Diclofenac & Methyleugenol + Diclofenac \\
\hline $\mathrm{C}_{\max }(\mu \mathrm{g} / \mathrm{mL})$ & $2.80 \pm 0.09$ & $1.83 \pm 0.18^{*}$ \\
$\mathrm{t}_{\frac{1}{2}}(\mathrm{~min})$ & $126.71 \pm 22.25$ & $103.87 \pm 12.11$ \\
$\mathrm{~T}_{\max }(\mathrm{min})$ & $6.00 \pm 0.55$ & $10.83 \pm 2.00$ \\
$\mathrm{AUC}_{0 \rightarrow \mathrm{t}}(\mu \mathrm{g} \times \mathrm{min} / \mathrm{mL})$ & $149.02 \pm 30.83$ & $158.76 \pm 19.83$ \\
$\mathrm{AUC}_{0 \rightarrow \infty}(\mu \mathrm{g} \times \mathrm{min} / \mathrm{mL})$ & $191.63 \pm 49.50$ & $189.05 \pm 27.39$ \\
\hline
\end{tabular}

Concerning the pharmacokinetics of ketorolac (Table 4), the $\mathrm{C}_{\max }$ for the individual treatment $(0.66 \pm 0.06 \mu \mathrm{g} / \mathrm{mL})$ was not significantly different from the value for methyleugenol plus ketorolac $(0.97 \pm 0.16 \mu \mathrm{g} / \mathrm{mL})$. Thus, the absorption of ketorolac was not modified in the combined treatment. The other pharmacokinetic parameters did not differ significantly between these two treatments either (Table 4).

Table 4. Parameters of the pharmacokinetics ascertained after oral administration of the vehicle plus ketorolac $(1.64 \mathrm{mg} / \mathrm{kg})$ or methyleugenol plus ketorolac $(1.9$ and $1.64 \mathrm{mg} / \mathrm{kg}$, respectively) to rats. Data represent the mean $\pm \operatorname{SEM}(n=6)$.

\begin{tabular}{ccc}
\hline Parameter & Ketorolac & Methyleugenol + Ketorolac \\
\hline $\mathrm{C}_{\max }(\mu \mathrm{g} / \mathrm{mL})$ & $0.66 \pm 0.06$ & $0.97 \pm 0.16$ \\
$\mathrm{t}_{\frac{1}{2}}(\mathrm{~min})$ & $39.45 \pm 5.45$ & $44.82 \pm 5.79$ \\
$\mathrm{~T}_{\max }(\mathrm{min})$ & $13.33 \pm 5.27$ & $10.00 \pm 2.33$ \\
$\mathrm{AUC}_{0 \rightarrow \mathrm{t}}(\mu \mathrm{g} \times \mathrm{min} / \mathrm{mL})$ & $39.77 \pm 4.01$ & $53.13 \pm 6.99$ \\
$\mathrm{AUC}_{0 \rightarrow \infty}(\mu \mathrm{g} \times \mathrm{min} / \mathrm{mL})$ & $41.29 \pm 4.51$ & $56.34 \pm 7.09$ \\
\hline
\end{tabular}




\section{Discussion}

Although NSAIDs are often prescribed to relieve pain and inflammation, their prolonged use has significant adverse effects [13]. One alternative to reduce such effects is to combine an NSAID with a prophylactic (e.g., a proton pump inhibitor). Another is the combination of two NSAIDs that act by distinct mechanisms of action. In the current contribution, the antinociceptive effect of the combination of an NSAID (diclofenac or ketorolac) with methyleugenol was examined on the formalin test. This test, based on the nociceptive response to chemical stimuli, is widely used to assess pain and preclinically evaluate analgesic drugs [14], due to its relative simplicity and high degree of reproducibility [15].

Methyleugenol, diclofenac, and ketorolac administered individually herein produced dose-dependent antinociception (Figure 1B,D,F), in agreement with previous reports [16-18]. The results showed significantly reduced licking behavior time in phase II of the test. This phase, involving both inflammatory mechanisms and central nervous system sensitization, is known to respond to various drugs with established clinical analgesic action (e.g., opiates, steroid or non-steroidal anti-inflammatory analgesics, N-methyl-D-aspartate antagonists, and gabapentin) [14]. Methyleugenol was more potent than diclofenac and equipotent with ketorolac, as indicated by the corresponding $\mathrm{ED}_{30}$ values (Table 1).

The combination of methyleugenol plus diclofenac demonstrated a dose-dependent effect (Figure 2C) and an additive-type antinociceptive interaction, the latter according to the isobolographic analysis (Figure 2E). Consequently, methyleugenol does not potentiate the effect of diclofenac. The additive interaction likely stems from the important shared signaling pathways of the antinociceptive activity of the two compounds including the inhibition of COX2 [12,19], the inactivation of NMDA [16,19], and the blocking of the upregulation of Nav1.7 [20,21].

The methyleugenol plus ketorolac combination showed a dose-dependent effect (Figure 2D) and a likely synergistic interaction, the latter evidenced by the isobolographic analysis (Figure 2F). Although ketorolac and methyleugenol have some common antinociceptive mechanisms of action, there are also substantial differences that could possibly explain the synergism in their interaction, whereas ketorolac inhibits COX1 and methyleugenol does not [12]; on the other hand, there are no reports that ketorolac blocks the upregulation of Nav1.7 channels or activates GABAA receptors and methyleugenol does.

Regarding the $\mathrm{C}_{\max }$ for diclofenac, the study of pharmacokinetics revealed a significantly lower value with the combined treatment than with the administration of diclofenac alone (Table 3). In contrast, there was no significant difference in the $\mathrm{C}_{\max }$ for methyleugenol plus ketorolac and ketorolac alone (Table 4). In both cases (methyleugenol plus diclofenac or ketorolac), the present results are in contrast with previously reported data by our work group [22], which demonstrated the inhibition of the absorption of diclofenac and ketorolac due to the combined treatment with methyleugenol. In the prior study, however, the dose of methyleugenol was higher $(100 \mathrm{mg} / \mathrm{kg}$ vs. $3.99 \mathrm{mg} / \mathrm{kg}$ given currently), as was the dose of ketorolac ( $10 \mathrm{mg} / \mathrm{kg}$ vs. $1.64 \mathrm{mg} / \mathrm{kg}$ employed presently), while the dose of diclofenac was lower $(10 \mathrm{mg} / \mathrm{kg}$ vs. $15.08 \mathrm{mg} / \mathrm{kg}$ administered currently).

The lower level of the $C_{\max }$ for diclofenac in the combination (versus individual) treatment was not a consequence of the presence of methyleugenol. Due to its lipophilic characteristics, methyleugenol has a rapid absorption [23] and thus does not modify gastric $\mathrm{pH}$. As it does not generate acidic conditions, it does not alter the absorption of drugs [22] such as diclofenac. The reduced absorption of diclofenac is probably explained by its precipitation per se, considering its acidic characteristics [24] and the dose administered $(15.08 \mathrm{mg} / \mathrm{kg})$. This should cause a greater redissolution and a decrease in the precipitated fraction $[25,26]$. The rate of dissolution of a drug in the gastrointestinal tract often partially or completely controls the rate of its absorption [27]. Regarding $\mathrm{T}_{\max }, \mathrm{t}_{1 / 2}$ and the AUC, no significant differences were observed between groups (Table 3). Therefore, the additive interaction between methyleugenol and diclofenac cannot be attributed to the pharmacokinetic interaction. In the same sense, the parameters of $\mathrm{t}_{1 / 2}, \mathrm{~T}_{\max }, \mathrm{AUC}$, and $\mathrm{C}_{\max }$ (Table 4) showed no significant difference between methyleugenol plus ketorolac and ketorolac alone, which indicates that methyleugenol does not interfere with the absorption of ketorolac. 
The differences in the mechanisms of action of methyleugenol and ketorolac could explain the apparent synergistic interaction involved in the combined treatment. Likewise, the similarity in the mechanisms of action of methyleugenol and diclofenac likely accounts for the additive effect of methyleugenol and diclofenac in the combined treatment.

\section{Material and Methods}

\subsection{Animals}

Male ICR mice (20-25 g) and Wistar rats (180-220 g) were obtained from our breeding facilities. The animals were housed in a vivarium under controlled conditions, with the temperature at $22-25^{\circ} \mathrm{C}$, air flow, a 12-h light/dark cycle, and free access to food and water. They were fasted for $18 \mathrm{~h}$ before the experiments. The care and handling of animals were conducted in accordance with the Mexican official guidelines for laboratory animals (NOM-062-ZOO-1999) [28] and the "Ethical guidelines for investigations of experimental pain in conscious animals" [29]. In addition, all animal experiments were approved by the institutional Ethics in Research Committee. Every effort was made to minimize the pain and suffering of the animals, utilizing the minimum number of animals for the statistical power needed to find a significant effect. Each assay was carried out with independent groups of animals, used only once, and euthanized in $\mathrm{CO}_{2}$ chamber at the end of the experiment.

\subsection{Drugs}

Formaldehyde, ketorolac, diclofenac, and methyleugenol were purchased from Sigma-Aldrich (St. Louis, MO, USA). Methanol and high-performance liquid chromatography (HPLC)-grade acetonitrile were acquired from JT Baker. Formaldehyde was freshly prepared in distilled water. Ketorolac and diclofenac were dissolved in saline solution $(0.9 \%)$, while methyleugenol was suspended in $0.05 \%$ Tween 80 .

\subsection{Formalin Test}

Mice were orally administered one of six treatments $(0.1 \mathrm{~mL} / 10 \mathrm{~g})$ : (1) the vehicle, a saline solution with $0.05 \%$ Tween 80 (the control); (2) methyleugenol (1-30 mg/kg); (3) diclofenac (1-30 mg/kg); (4) ketorolac (1-30 mg/kg); (5) methyleugenol plus diclofenac; and (6) methyleugenol plus ketorolac. The $2.5 \%$ formalin test was conducted $30 \mathrm{~min}$ after the animals received each treatment. Formalin-induced licking behavior in mice was evaluated as previously described [30]. Briefly, each mouse was placed in an open plastic observation chamber for $30 \mathrm{~min}$ to become acclimated to its surroundings. Subsequently, it was removed, injected with $20 \mu \mathrm{L}$ of $2.5 \%$ formalin into the dorsum of the right hindpaw, and returned to the chamber. The accumulated time spent licking the injected paw was taken as nociceptive behavior. Animal behavior was observed during phase I (from 1-10 min) and phase II (from 11-40 min). A brief timeline of the experimental design is given in Figure 3.

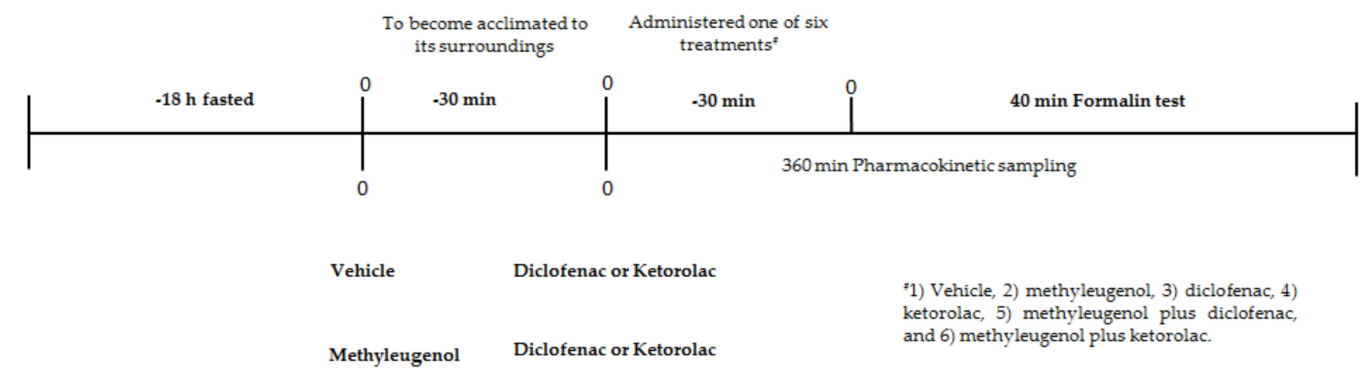

Figure 3. Timeline of the experimental design. 


\subsubsection{Data Analysis from the Formalin Test}

The results of this assay are expressed as the mean \pm standard error of the mean (SEM) of 6-8 animals. The curve for the time course of the activity of each drug dose was constructed by plotting the licking time against the log dose. The percentage of the antinociceptive effect was calculated from the total licking time evoked during phase II, in accordance with the following equation:

$$
\% \text { Antinociception }=\frac{\text { Control licking time }- \text { Test licking time }}{\text { Control licking time }} \times 100
$$

The statistical differences between groups with regard to the dose-response curves were determined by one-way analysis of variance (ANOVA) followed by Dunnett's test.

\subsubsection{Isobolographic Analysis}

The $\mathrm{ED}_{30}$ for each drug administered individual was calculated from its dose-response curve by linear regression. The isobologram was then constructed by plotting the $\mathrm{ED}_{30}$ value of methyleugenol on the abscissa and the $\mathrm{ED}_{30}$ value of diclofenac or ketorolac on the ordinate to obtain the theoretical additive line. The theoretical $\mathrm{ED}_{30} \mathrm{~T}$ value for each combination was calculated and the dose-response curve was constructed based on fractions $(1 / 2,1 / 4,1 / 8 \mathrm{~m}$ and $1 / 16)$ of the $\mathrm{ED}_{30}$ values of the individual drugs, using a 1:1 dose ratio. Afterward, the experimental $E_{30} E$ value of each combination was calculated from its corresponding dose-response curve by linear regression. The difference between each $\mathrm{ED}_{30} \mathrm{~T}$ and the respective $\mathrm{ED}_{30} \mathrm{E}$ was examined by the Student's t-test. Interaction indices $(\gamma)$ and confidence intervals for the $\mathrm{ED}_{30}$ were calculated as described by Tallarida [31,32].

\subsection{Evaluation of Pharmacokinetics}

The parameters of the pharmacokinetics of diclofenac and ketorolac were ascertained in four groups of rats. Two groups (the controls) received $0.05 \%$ Tween 80, and $30 \mathrm{~min}$ later, $15.08 \mathrm{mg} / \mathrm{kg}$ of diclofenac or $1.64 \mathrm{mg} / \mathrm{kg}$ of ketorolac. The other two groups received methyleugenol at a dose of 3.99 or $1.9 \mathrm{mg} / \mathrm{kgm}$ and $30 \mathrm{~min}$ later $15.08 \mathrm{mg} / \mathrm{kg}$ of diclofenac or $1.64 \mathrm{mg} / \mathrm{kg}$ of ketorolac, respectively. All treatments were administered orally and in a volume of $0.5 \mathrm{~mL} / 100 \mathrm{~g}$. Blood samples of 200 microliters were drawn as previously reported [22]. Briefly, the animals were subjected to cannulation of the caudal artery, employing a PE-10 catheter (rinsed with heparin) to extract 200 microliters of blood. The samples were taken at 2.5, 5.7, 5, 10, 15, 30, 45, 60, 120, 240, and $360 \mathrm{~min}$ post-administration of diclofenac, and at $0,5,15,30,45,60,120,180,240$, and $360 \mathrm{~min}$ post-delivery of ketorolac. Immediately after drawing a blood sample, the same volume of physiological isotonic saline was injected to avoid hypovolemia. Each sample was centrifuged, frozen, and left in cold storage to await further use. A brief timeline of the experimental design is illustrated in Figure 3.

\subsubsection{Quantifying the Plasma Concentration of Diclofenac and Ketorolac}

The drugs were assayed by HPLC on a Waters system to assess the plasma concentration of diclofenac and ketorolac, as previously described (with slight modifications) [22]. Briefly, reversed phase chromatography was used for drug analysis. Ketorolac was examined in a Zorbax Eclipse Plus C18 column $(150 \times 4.6 \mathrm{~mm}, 4.5 \mu \mathrm{m})$ using a mobile phase of $0.04 \mathrm{M}$ phosphate buffer:acetonitrile:methanol 60:20:20 $(v / v / v)$ delivered at a flow rate of $1.4 \mathrm{~mL} / \mathrm{min}$. Diclofenac was evaluated in a Symmetry C18 Waters column $(150 \times 4.6 \mathrm{~mm}, 5 \mu \mathrm{m})$, with a mobile phase of 0.041 M phosphate buffer:acetonitrile:methanol 49:51 (v/v) at a flow rate of $1.4 \mathrm{~mL} / \mathrm{min}$. The lower limit of quantification was $0.5 \mu \mathrm{g} / \mathrm{mL}$ for diclofenac and $0.05 \mu \mathrm{g} / \mathrm{mL}$ for ketorolac. For diclofenac, the intra- and inter-day precision coefficients of variation (CV) were less than $3.86 \%$ and $5.97 \%$, respectively. The accuracy of the intra- and inter-day determinations was 93.62-100.82\% and 95.80-99.8\%, respectively. For ketorolac, the intra- and inter-day precision CV were less than $8.45 \%$ 
and $10.03 \%$, respectively. The accuracy of the intra- and inter-day determinations was $96.87-119.14 \%$ and $93.75-108.3 \%$, respectively.

\subsubsection{Non-Compartmental Analysis}

The non-compartmental pharmacokinetic parameters, estimated by Phoenix ${ }^{\circledR}$ (WinNonlin ${ }^{\circledR}$ ver 8.1), were the terminal half-life $\left(t_{1 / 2}\right)$, peak plasma concentration $\left(C_{\max }\right)$, time to reach $C_{\max }\left(T_{\max }\right)$, and area under the plasma concentration vs. time curve from time zero to the last observation time $\left(\mathrm{AUC}_{0 \rightarrow \mathrm{t}}\right)$ and from time zero to infinity $\left(\mathrm{AUC}_{0 \rightarrow \infty}\right)$. Data were expressed as the mean $\pm \mathrm{SEM}$ and examined with unpaired t-tests for comparisons between two means, considering statistical significance at $p<0.05$.

\section{Conclusions}

The results of the evaluation of the analgesic activity of diclofenac, ketorolac, and methyleugenol administered individually coincide with the reported data. The combination of methyleugenol and ketorolac, according to the current findings, likely produces a synergistic effect. In such a case, it should be useful in the treatment of inflammatory pain. In contrast, the combination of methyleugenol and diclofenac had an additive effect, whereas the mechanisms of action of methyleugenol and diclofenac are very similar, and those of methyleugenol and ketorolac exhibit important differences, which is probably the best explanation for the aforementioned drug interactions. Further research is needed to provide greater clarity about the mechanisms involved in the interactions of the compounds in these combinations.

Author Contributions: M.E.S.-M. and H.I.R.-G. conceived and designed the experiments; X.I.C.-H. performed the experiments; L.C.-A. and F.J.F.-M. analyzed the data and contributed to the preparation of the manuscript; H.I.R.-G. and J.A. were responsible for the writing, review, and editing of the manuscript. All authors have read and agreed to the published version of the manuscript.

Funding: This research was supported by grants (SIP 20201001 and SIP 20200425) from the Escuela Superior de Medicina of the Instituto Politécnico Nacional, Mexico.

Acknowledgments: The authors wish to thank Alvaro Bouret Araiza, Erik Arturo Torres Trejo, and Joyce Chinas Orozco for their technical assistance.

Conflicts of Interest: The authors declare no conflict of interest.

\section{References}

1. Williams, A.C.; Craig, K.D. Updating the definition of pain. Pain 2016, 157, 2420-2423. [CrossRef]

2. Mickle, A.D.; Shepherd, A.J.; Mohapatra, D.P. Nociceptive TRP Channels: Sensory Detectors and Transducers in Multiple Pain Pathologies. Pharmaceuticals 2016, 9, 72. [CrossRef] [PubMed]

3. Da Silva, J.T.; Seminowicz, D.A. Neuroimaging of pain in animal models: A review of recent literature. Pain Rep. 2019, 4, e732. [CrossRef]

4. Woolf, C.J. Pain: Moving from symptom control toward mechanism-specific pharmacologic management. Ann. Intern. Med. 2004, 140, 441-451. [CrossRef]

5. Singh, A.K.; Kumar, S.; Vinayak, M. Recent development in antihyperalgesic effect of phytochemicals: Anti-inflammatory and neuro-modulatory actions. Inflamm. Res. 2018, 67, 633-654. [CrossRef]

6. Leith, J.L.; Wilson, A.W.; Donaldson, L.F.; Lumb, B.M. Cyclooxygenase-1-derived prostaglandins in the periaqueductal gray differentially control C-versus A-fiber-evoked spinal nociception. J. Neurosci. 2007, 27, 11296-11305. [CrossRef] [PubMed]

7. Bakhriansyah, M.; Souverein, P.C.; de Boer, A.; Klungel, O.H. Gastrointestinal toxicity among patients taking selective COX-2 inhibitors or conventional NSAIDs, alone or combined with proton pump inhibitors: A case-control study. Pharmacoepidemiol. Drug. Saf. 2017, 26, 1141-1148. [CrossRef] [PubMed]

8. Crofford, L.J. Use of NSAIDs in treating patients with arthritis. Arthritis. Res. Ther. 2013, 15, S2. [CrossRef] [PubMed] 
9. Grosser, T.; Ricciotti, E.; FitzGerald, G.A. The Cardiovascular Pharmacology of Nonsteroidal Anti-Inflammatory Drugs. Trends Pharmacol Sci. 2017, 38, 733-748. [CrossRef] [PubMed]

10. Rostom, A.; Muir, K.; Dubé, C.; Jolicoeur, E.; Boucher, M.; Joyce, J.; Tugwell, P.; Wells, G. Gastrointestinal Safety of Cyclooxygenase-2 Inhibitors: A Cochrane Collaboration Systematic Review. Clin. Gastroenterol. Hepatol. 2007, 5, 818-828. [CrossRef]

11. Raffa, R.B.; Pergolizzi, J.V., Jr.; Tallarida, R.J. The determination and application of fixed-dose analgesic combinations for treating multimodal pain. J. Pain 2010, 11, 701-709. [CrossRef] [PubMed]

12. Tang, F.; Chen, F.; Ling, X.; Huang, Y.; Zheng, X.; Tang, Q.; Tan, X. Inhibitory effect of methyleugenol on IgE-mediated allergic inflammation in RBL-2H3 cells. Mediat. Inflamm. 2015, 2015, 463530. [CrossRef]

13. Tramèr, M.R.; Moore, R.A.; Reynolds, D.J.; McQuay, H.J. Quantitative estimation of rare adverse events which follow a biological progression: A new model applied to chronic NSAID use. Pain 2000, 85, 169-182. [CrossRef]

14. Barrot, M. Tests and models of nociception and pain in rodents. Neuroscience 2012, 211, 39-50. [CrossRef]

15. Allen, J.W.; Yaksh, T.L. Tissue injury models of persistent nociception. In Pain Research Methods and Protocols Rats; Luo, Z.D., Ed.; Humana Press: Totowa, NJ, USA, 2004; pp. 25-26.

16. Yano, S.; Suzuki, Y.; Yuzurihara, M.; Kase, Y.; Takeda, S.; Watanabe, S.; Aburada, M.; Miyamoto, K.I. Antinociceptive effect of methyleugenol on formalin-induced hyperalgesia in mice. Eur. J. Pharmacol. 2006, 553, 99-103. [CrossRef]

17. Ortiz, M.I. Blockade of the antinociception induced by diclofenac, but not of indomethacin, by sulfonylureas and biguanides. Pharmacol. Biochem. Behav. 2011, 99, 1-6. [CrossRef]

18. Rodríguez-Silverio, J.; Sánchez-Mendoza, M.E.; Arrieta-Valencia, J.; Rocha-González, H.I.; Flores-Murrieta, F.J. Tizanidine Increases Antinociceptive Effect and Prevents Gastric Damage Induced by Ketorolac in the Rat. Drug Dev. Res. 2013, 74, 38-42. [CrossRef]

19. Ortiz, M.I.; Granados-Soto, V.; Castañeda-Hernández, G. The NO-cGMP-K+ channel pathway participates in the antinociceptive effect of diclofenac, but not of indomethacin. Pharmacol. Biochem. Behav. 2003, 76, 187-195. [CrossRef]

20. Bi, R.Y.; Ding, Y.; Gan, Y.H. Non-steroidal Anti-inflammatory Drugs Attenuate Hyperalgesia and Block Upregulation of Trigeminal Ganglionic Sodium Channel 1.7 after Induction of Temporomandibular Joint Inflammation in Rats. Chin. J. Dent. Res. 2016, 19, 35-42. [PubMed]

21. Wang, Z.J.; Tabakoff, B.; Levinson, S.R.; Heinbockel, T. Inhibition of Nav1.7 channels by methyl eugenol as a mechanism underlying its antinociceptive and anesthetic actions. Acta. Pharmacol. Sin. 2015, 36, 791-799. [CrossRef]

22. Cruz-Antonio, L.; Sánchez-Mendoza, M.E.; López-Lorenzo, Y.; Rocha-González, H.I.; Robles-Sánchez, A.; Arrieta, J. Pharmacokinetics Effect of Diclofenac or Ketorolac-methyl Eugenol and Their Implication in the Gastroprotection. Int. J. Pharmacol. 2020, 16, 375-381.

23. Committee on Herbal Medicinal Products (HMPC). Public Statement on the Use of Herbal Medicinal Products Containing Methyleugenol. 2005. Available online: https://www.ema.europa.eu/en/documents/scientificguideline/public-statement-use-herbal-medicinal-products-containing-methyleugenol_en.pdf (accessed on 5 May 2020).

24. Adeyeye, C.M.; Li, P.K. Diclofenac Sodium. In Analytical Profiles of Drug Substances; Florey, K., Ed.; Academic Press Inc.: New York, NY, USA, 1990; pp. 123-144.

25. Yuan, J.; Ma, H.; Cen, N.; Zhou, A.; Tao, H. A pharmacokinetic study of diclofenac sodium in rats. Biomed. Rep. 2017, 7, 179-182. [CrossRef]

26. Peris-Ribera, J.E.; Torres-Molina, F.; Garcia-Carbonell, M.C.; Aristorena, J.C.; Pla-Delfina, J.M. Pharmacokinetics and bioavailability of diclofenac in the rat. J. Pharm. Biopharm. 1991, 19, 647-665. [CrossRef] [PubMed]

27. Mudie, D.M.; Amidon, G.L.; Amidon, G.E. Physiological parameters for oral delivery and in vitro testing. Mol. Pharm. 2010, 7, 1388-1405. [CrossRef]

28. Norma Oficial Mexicana NOM-062-ZOO-1999. Available online: https:/www.gob.mx/cms/uploads/ attachment/file/203498/NOM-062-ZOO-1999_220801.pdf (accessed on 12 October 2020).

29. Zimmermann, M. Ethical guidelines for investigation of experimental pain in conscious animals. Pain 1983, 16, 109-110. [CrossRef] 
30. González-Trujano, M.E.; Peña, E.I.; Martínez, A.L.; Moreno, J.; Guevara-Fefer, P.; Déciga-Campos, M.; López-Muñoz, F.J. Evaluation of the antinociceptive effect of Rosmarinus officinalis L. using three different experimental models in rodents. J. Ethnopharmacol. 2007, 111, 476-482.

31. Tallarida, R.J. Calculations for combination drug analysis. In Drug Synergism and Dose-Effect Data Analysis; Chapman and Hall/CRC: New York, NY, USA, 2000; pp. 57-71.

32. Tallarida, R.J. The interaction index: A measure of drug synergism. Pain 2002, 98, 163-168. [CrossRef]

Sample Availability: Not available.

Publisher's Note: MDPI stays neutral with regard to jurisdictional claims in published maps and institutional affiliations.

(C) 2020 by the authors. Licensee MDPI, Basel, Switzerland. This article is an open access article distributed under the terms and conditions of the Creative Commons Attribution (CC BY) license (http://creativecommons.org/licenses/by/4.0/). 